\title{
Rendimento e análise bromatológica do lambari do rabo vermelho Astyanax sp F (Pisces: characidae) submetido ao processo de defumação
}

\section{Performance and bromatologic analysis of red tail lambari Astyanax $s p$ F (Pisces: characidae) submitted to the smoking process}

\author{
Aldi Feiden ${ }^{1 *}$; Takeo Massago ${ }^{2}$; Wilson Rogério Boscolo ${ }^{3}$; \\ Arcangelo Augusto Signor ${ }^{4}$; Aline Luna Zorzo ${ }^{5}$; Carlos Eduardo Weirich ${ }^{6}$
}

\section{Resumo}

\begin{abstract}
O objetivo do presente trabalho foi avaliar o tempo de defumação a quente e a influência sobre a qualidade de carcaça de lambaris Astyanax sp. F. Foram utilizados 60 lambaris, com peso e comprimento médio de $22,22 \pm 4,32 \mathrm{~g}$ e $11,32 \pm 0,63 \mathrm{~cm}$, eviscerados e com cabeça, pele, espinhas, coluna vertebral, nadadeiras, porém, sem escamas. Os animais foram submetidos à salga úmida $(25 \%$ de cloreto de sódio por 45 minutos) e condimentos, sendo posteriormente defumados a quente, por um período de $90,180,270$ e 360min. Após o processo de defumação, os peixes foram pesados e posteriormente calculados os teores de umidade, proteína bruta, lipídeos e matéria mineral da carcaça dos animais. Os resultados mostraram diferenças $(\mathrm{P}<0,01)$ para rendimento, apresentando o melhor aproveitamento para o tempo de 90 min seguido dos tratamentos 180 e 270min, mas apresentou efeito LRP (linear Response Plateau) para tempo de $225 \mathrm{~min} 7 \mathrm{seg}$, demonstrando que os tratamentos intermediários apresentaram melhor rendimento. Quanto aos teores de proteína, lipídeos e matéria mineral, não houve diferenças $(\mathrm{P}>0,05)$ entre os diferentes tempos de defumação. Portanto, conclui-se que para o Astyanax sp F o tempo de defumação de $225 \mathrm{~min} 7 \mathrm{seg}$ é o período de defumação indicado para o melhor produto final.

Palavras-chave: Agregação de valor, peixes nativos, processamento de pescados, tecnologia do pescado.
\end{abstract}

\begin{abstract}
The aim of this study was to evaluate the time of hot smoked and the influence of carcass quality of the red tail lambari Astyanax sp F. Sixty lambaris, eviscerated with head, skin, bones, spinal column, fins, however, without scale. With a medium weight and length of $22.22 \pm 4.32 \mathrm{~g}$ and $11.32 \pm 00.63 \mathrm{~cm}$ were utilized. The animals were submitted to humid salted (25\% of sodium chloride for 45 minutes) and condiments, been later hot smoked for a period of 90, 180, 270, $360 \mathrm{~min}$. After the smoking process, the fish were weighted and later the humidity tenor, gross protein, lipids and mineral matter of the carcass of the animals were calculated. The results showed differences $(\mathrm{P}<0.01)$ for performance, presenting the best use for the time of $90 \mathrm{~min}$ followed by treatments of 180 and $270 \mathrm{~min}$, but presented LRP (linear Response Plateau) for the time of 225:07 min, demonstrating that the intermediate treatments
\end{abstract}

\footnotetext{
1 Engenheiro Agrônomo; Professor Adjunto - UNIOESTE/Toledo, Rua da Faculdade 645, Jardim La Salle. CEP 85903-000.

E-mail: feiden@seti.pr.gov.br

2 Engenheiro de Pesca-UNIOESTE/Toledo.

3 Zootecnista; Professor Adjunto - UNIOESTE/Toledo. E-mail: wilsonboscolo@hotmail.com

4 Engenheiro de Pesca - Doutorando em Zootecnia/UEM/Maringá. E-mail: angelo_signor@hotmail.com.

5 Acadêmica do Curso de Química Bacharel - UNIOESTE/Toledo. E-mail: aline_1_zorzo@hotmail.com.

6 Biólogo - UNIPAR/ Toledo. E-mail: carlosweirich@yahoo.com.br.

Autor para correspondência
} 
presented good performance. For the protein tenor, lipids and mineral matter, there were no differences $(\mathrm{P}<0.05)$ between the different smoking time. Therefore, it can be concluded that the smoking time of $225 \mathrm{~min} 7 \mathrm{seg}$ for the Astyanax sp F, is the indicated smoking time for the best final product.

Key words: Value aggregation, native fish, fisheries technology, fisheries processing

\section{Introdução}

O lambari do rabo amarelo (Astianax altiparanae) é um peixe muito comum em córregos e lagos das bacias hidrográficas brasileiras, pertencentes à família Characidae, sendo um grupo de espécies estritamente de água doce. Na ictiofauna do baixo rio Iguaçu/Paraná, possui cinco espécies de lambaris do gênero Astyanax, que são dominantes em número de indivíduos capturados (CASSEMIRO; HAHN; FUGI, 2002). O lambari do rabo vermelho Astyanax sp F é uma espécie endêmica do rio Iguaçu, com bom potencial para a pesca, apresentando rápido crescimento e alto valor comercial. Segundo Reidel et al. (2005) apresenta rendimento de carcaça de $88 \%$ para peixes entre 10 a $20 \mathrm{~g}$ e Boscolo et al. (2005) esta espécie apresenta rendimento superior a $86 \%$, o que é muito representativo para estes animais de peso relativamente pequeno.

As estatísticas mostram baixo consumo de pescado (SCHMIDT, 2004), e uma das maneiras de incrementaro consumo sãoas formas de apresentação dos produtos, uma vez que o consumidor busca um alimento de preparo rápido (SOUZA et al., 2004), sem o inconveniente de descartar os resíduos. Uma das alternativas de incrementar o consumo é a defumação do pescado, mas apenas $2 \%$ da produção mundial é destinado à esta forma de preparo, sendo que no Brasil a produção desse tipo de produto, é muito restrita, principalmente para peixes de água doce (NUNES, 1999).

Segundo Oliveira e Inhamuns (2005), o produto defumado é considerado nobre, não havendo uma produção em escala industrial que possa competir com os pescados importados. Os peixes de porte pequeno normalmente são defumados inteiros eviscerados e, os maiores, em filés, pedaços ou partes, borboleta ou espalmado, postas ou tronco limpo, sendo os cortes com ou sem pele (SOUZA et al., 2005).

A defumação é o processo de submeter os alimentos ao efeito dos gases e vapor de queima de madeiras com objetivo de conservação e obtenção nas particularidades organolépticas agradáveis. No entanto, existem três fases distintas imprescindíveis para se obter a boa qualidade de produto: salmouragem, secagem e a defumação. Segundo Souza et al. (2004), o êxito na preparação de defumados depende da aplicação da fumaça e da combinação de fatores físicos e químicos, sendo necessário um controle rigoroso de cada uma das etapas da defumação. A defumação pode ser considerada um método para a conservação do pescado, porém, é importante atentar para o fato de que o efeito preservativo da fumaça é insuficiente. Se a defumação não é combinada com outros métodos de preservação tais como a salga e secagem ou congelamento, o produto defumado permanece bom para o consumo por um período um pouco maior do que o pescado fresco, e a principal função da defumação é a de fornecer ao pescado um sabor característico e agradável ao paladar.

O sabor de defumado é obtido através dos compostos fenólicos que podem influenciar no produto. O sabor deve-se também ao efeito do sal, umidade do produto, temperatura, tempo e materiais usados para gerar a fumaça. Os conservantes da fumaça são compostos bactericidas e bacteriostáticos, como formaldeídos, fenóis e ácidos orgânicos, que inibem a ação bacteriana, e impedem ação antioxidante. Beraquet e Mori (1984) afirmam que o tempo de exposição do filé à fumaça acentua seu sabor, pela presença de compostos fenólicos, principalmente do 4 metilguaiacol. 
Segundo Souza et al. (2004), existem dois tipos de defumação que são: defumação à quente e à frio. $\mathrm{O}$ pescado destinado a defumação a frio apresenta baixo teor da umidade (40\%) e conteúdo de sal relativamente elevado ( 7 a 15\%), a ocorrência de secagem prolongada aumenta sua vida útil, porém, a temperatura não pode exercer a $40^{\circ} \mathrm{C}$, para a defumação à quente recomenda-se que a temperatura seja entre 50 e $70^{\circ} \mathrm{C}$, com umidade do produto de 55 a $65 \%$. Ferreira et al. (2002), relata que na defumação a frio a temperatura é inferior a $40^{\circ} \mathrm{C}$ e defumação a quente entre $50-120^{\circ} \mathrm{C}$.

Peixes gordurosos são os mais indicados para a defumação melhorando suas características organolépticas e agregando valor ao produto final, que utiliza geralmente estes espécies, tais como: mandis, bagre, sardinha, cascudos, anchoveta, manchete, cavalo e merluza, por adquirir um melhor aspectos depois de defumado, pois as gotículas de gordura ajudam na retenção da fumaça, conferindo aroma e sabor agradável ao produto (SANCHEZ, 1989). Por outro lado, os peixes magros podem ser utilizados para a defumação, como a tilápia. De acordo com Sanchez (1989), as gotículas de gordura ajudam a reter os compostos aromáticos da fumaça que além de conferir odor e sabor agradável, aumentam a durabilidade dos mesmos, por lubrificálos, impedindo a desidratação.

O valor nutricional (proteínas e lipídios) do pescado defumado é superior ao produto in natura pois a ação da fumaça resulta em perda excessiva de umidade, concentrando a proteína e lipídios (GONÇALVES; PRENTICE-HERNANDEZ, 1998; MACEDO-VEIGAS; SOUZA, 2004; SOUZA et al., 2004, 2005).

O objetivo do presente trabalho é avaliar o tempo de defumação a quente e sua influência sobre a qualidade de carcaça de lambaris Astyanax sp. F.

\section{Materiais e métodos}

O experimento foi realizado no laboratório de Tecnologia do Pescado da Universidade Estadual do Oeste do Paraná - Campus de Toledo - Paraná, durante o mês de novembro de 2005.

Foram utilizados 60 lambaris do rabo vermelho Astyanax sp. F, de um total de 120, pescados com rede de malha $2 \mathrm{~mm}$ no reservatório de Governador José Richa, no rio Iguaçu. Os lambaris foram dessensibilizados com choque térmico através de gelo numa caixa isotérmica, posteriormente foram transportados para o Laboratório. Após três horas no gelo, foram lavados para retirada do muco e eviscerados. Foram então separados por classe de tamanho e escolhidos 60 semelhantes, com comprimento e peso médio de $11,32 \pm 0,62 \mathrm{~cm} \mathrm{e}$ $22,22 \pm 4,31 \mathrm{~g}$, respectivamente.

Após a pesagem foram eviscerados e lavados para eliminação de sangue proveniente do abate, e remoção do resto de sangue e vísceras que poderiam contribuir para a sua deterioração. Os peixes foram utilizados apresentavam cabeça, pele, espinhas, coluna vertebral e nadadeiras, porém, as escamas foram retiradas. Posteriormente foram numerados com uma placa de alumínio, para sua identificação e submetidos ao processo de salga úmida $(25 \%$ de cloreto de sódio por 45 minutos). A esta salmoura foram adicionados temperos tais como: salsa, cebolinha verde, cebola e alho. Após a retirada da salga foi efetuada uma lavagem rápida na superfície do pescado visando reduzir a quantidade de sal. Os mesmos permaneceram em bandejas plásticas para a drenagem por 30 minutos. Posteriormente todos os peixes foram fixados com arame e dispostos aleatoriamente em um defumador industrial vertical com capacidade para $20 \mathrm{~kg}$.

Os peixes foram separados em quatro grupos de quinze pescados cada, os quais foram expostos a diferentes tempos de exposição à fumaça no defumador, que constituem nos tratamentos 
experimentais: A) $90 \mathrm{~min}$ (1:30 horas); B) $180 \mathrm{~min}$ (3:00 horas); C) $240 \mathrm{~min}$ (4:30 horas) e D) $360 \mathrm{~min}$ (6:00 horas). O material comburente utilizado foi o pó de serra de madeiras que não resinosas, pois estas liberam substâncias que comprometem a qualidade do produto final.

A temperatura inicial do defumador foi de $50^{\circ} \mathrm{C}$ durante 30 minutos e de aproximadamente $80^{\circ} \mathrm{C}$ até o final do período de defumação. A temperatura foi monitorada a cada 15 minutos, e quando excedia a temperatura ideal foi borrifado água para sua redução da temperatura.

Encerrado o período de defumação os peixes foram pesados para análise de rendimento, embalados e refrigerados $\left(5^{\circ} \mathrm{C}\right)$ para posterior análise de composição química da carcaça. As análises bromatológicas de umidade (UM), matéria seca (MS), proteína bruta (PB), lipídios (LI) e matéria mineral (MM) foram realizados segundo a metodologia de descrita na AOAC (HORWITZ, 2000).

Os dados obtidos foram submetidos à análise de variância (ANOVA) e em caso de diferenças estatísticas foi aplicado o teste de Tukey, a 1\% $(\mathrm{P}<0,01)$ para rendimento e o efeito LRP (linear Response Plateau $)$ e o teste de Tukey a $5 \%(\mathrm{P}<0,05)$ para os demais parâmetros, utilizando-se programa estatístico SAEG (Sistemas de Analises Estatísticas e Genéticas) (UNIVERSIDADE FEDERAL DE VIÇOSA - UFV, 1997).

\section{Resultados e discussão}

Os valores de temperatura durante o processo de defumação variaram de 50 a $100^{\circ} \mathrm{C}$, conforme demonstrado na figura 1.

\section{Temperatura}

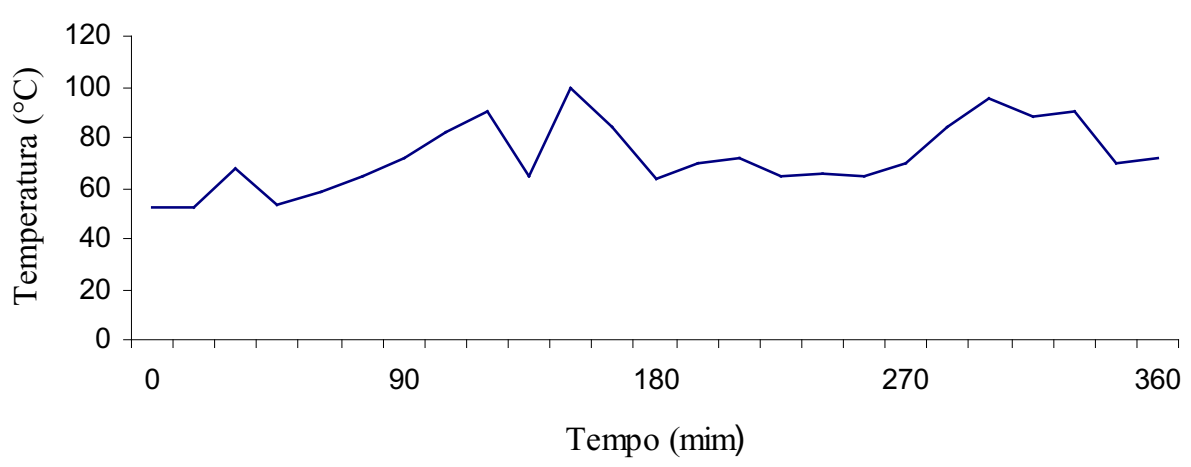

Figura 1. Variação da temperatura durante a defumação dos lambaris do rabo vermelho Astianax sp F.

A temperatura utilizada no processo foi à quente. Segundo Schmidt (2004), a temperatura semelhante ao relatado por Nunes (1999) e Schmidt deve ser inferior a $60^{\circ} \mathrm{C}$ somente por 30 minutos (2004), que afirmaram que para métodos da defumação a quente, a temperatura ideal é de $50^{\circ} \mathrm{C}$ a $70^{\circ} \mathrm{C}$, podendo chegar até $90^{\circ} \mathrm{C}$, porém, neste experimento a temperatura atingiu $100^{\circ} \mathrm{C}$. Por outro lado, está dentro da faixa definida por Ferreira et al. (2002), que varia de 50 a $120^{\circ} \mathrm{C}$ para defumação para uma secagem parcial, o que ocorreu no presente trabalho.

As medias de comprimento corporal total $\mathrm{e}$ padrão $(\mathrm{cm})$, peso corporal total $(\mathrm{g})$, peso corporal eviscerado $(\mathrm{g})$ e rendimento (\%) da defumação dos lambaris estão apresentadas na tabela 1 . 
Tabela 1. Valores médios das variáveis analisadas do lambari do rabo vermelho Astyanax sp F submetido a defumação em diferentes tempos de exposição a fumaça.

\begin{tabular}{lccccc}
\hline \multirow{2}{*}{ Variáveis } & \multicolumn{4}{c}{ Tratamentos (minutos) } & \multirow{2}{*}{ C.V. (\%) } \\
\cline { 2 - 5 } & 90 & 180 & 270 & 360 & \\
\hline Comprimento corporal total $(\mathrm{cm})$ & 11,53 & 11,32 & 11,63 & 11,28 & 5,54 \\
Comprimento corporal padrão (cm) & 9,32 & 9,10 & 9,41 & 9,06 & 6,23 \\
Peso corporal total inicial (g) & 22,22 & 20,17 & 22,48 & 21,29 & 19,44 \\
Peso corporal eviscerado inicial (g) & 19,31 & 18,17 & 19,53 & 17,79 & 19,85 \\
Rendimento da defumação (\%) & 69,45 & 52,25 & 47,02 & 40,23 & 10,993 \\
\hline
\end{tabular}

${ }^{1}$ Efeito linear Response Plateau $\mathrm{Y}=86,6549-0,1911 \mathrm{x} ; \mathrm{r}^{2}=0,74$, Plateau 225min7seg.

Foi observado efeito linear decrescente para o rendimento dos peixes defumados em função do tempo de defumação. Através da analise de LRP foi observado que o melhor rendimento foi apresentado nos tratamentos intermediários, pois o platô se estabiliza em 225min7seg com $\mathrm{r}^{2}$ de 0,74 (Figura 2). O aumenta no tempo de exposição à fumaça diminui a umidade e conseqüentemente rendimento, mas aumenta a qualidade do produto final.

Rendimento de defumação

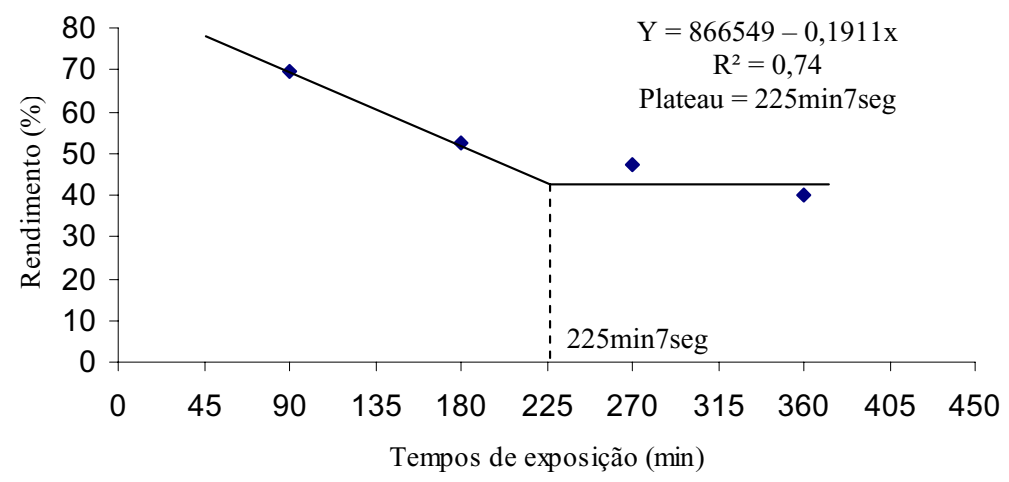

Figura 2. Rendimento da defumação em função do tempo de defumação dos lambaris do rabo vermelho Astianax sp F.

O valor médio de rendimento observado na defumação do lambari está de acordo com Nunes (1999), onde relata que o arenque apresenta rendimento de 39 a $75 \%$ para peixes pequenos, 42 a $67 \%$ para peixes médios e 51 a $78 \%$ para peixes grandes e de 40 a $50 \%$ de rendimento para o surubim inteiro eviscerado. Schmidt (2004) avaliando a defumação do filé de tilápia à quente com e sem of flavor em duas concentrações de sal, obteve rendimentos entre 56,24 e $58,65 \%$. Souza et al. (2005), observaram 22,97, 24,51 e 24,68\% de rendimento de filés defumados para peixes com 500$600,601-700$ e $701-800 \mathrm{~g}$ de peso e 25,17 e $22,72 \%$ de rendimento para filés com e sem pele. Souza et al. (2004) observaram $63,33 \%$ de rendimento da tilápia inteira defumada e $27,11 \%$ para filé defumados.

Os valores médios dos parâmetros de umidade (UM), proteína bruta (PB), lipídios (LP) e matéria mineral (MM) obtidas nas análises bromatológicas estão apresentados na Tabela 2. 
Tabela 2. Valores médios dos parâmetros da análise bromatológica do lambari do rabo vermelho Astyanax sp. F submetido a defumação.

\begin{tabular}{|c|c|c|c|c|c|}
\hline \multirow{2}{*}{ Parâmetros (\%) } & \multicolumn{4}{|c|}{ Tratamentos (minutos) } & \multirow{2}{*}{ C.V. $(\%)$} \\
\hline & 90 & 180 & 270 & 360 & \\
\hline Umidade $^{1}$ & 61,91 & 40,31 & 38,90 & 31,63 & 9,35 \\
\hline Proteína bruta & 26,26 & 26,16 & 28,26 & 28,12 & 5,737 \\
\hline Lipídios & 3,84 & 2,95 & 2,53 & 3,60 & 55,831 \\
\hline Materia mineral & 10,83 & 12,11 & 13,46 & 13,53 & 26,65 \\
\hline
\end{tabular}

${ }^{1}$ Efeito linear, $\mathrm{Y}=-0,1025 \mathrm{x}+66,25, \mathrm{r}^{2}=0,83$

Foi observado efeito linear decrescente para a UM (Figura 3) da carcaça dos peixes em função dos tratamentos experimentais, com maior valor para 90 minutos de defumação $(61,91 \%)$, que reduzem conforme o aumento no tempo de exposição dos animais a fumaça. O maior tempo de defumação (360 minutos) proporcionou um produto muito seco e quebradiço, de aspecto e cor indesejáveis para o consumo.

Umidade

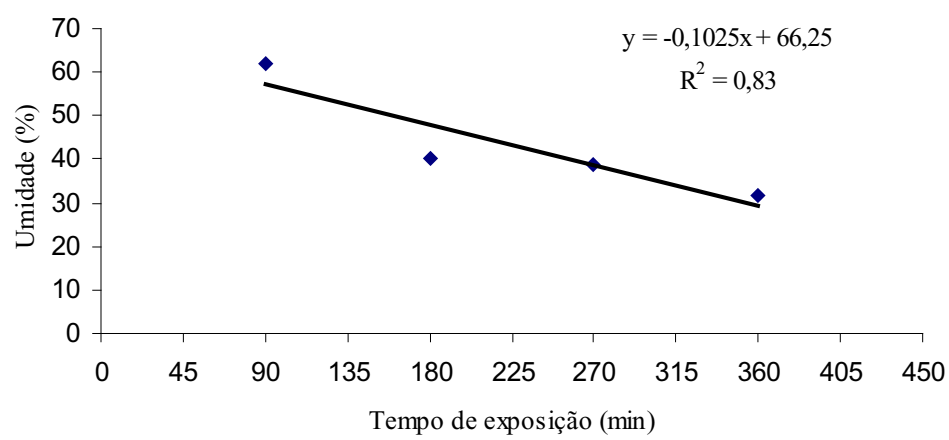

Figura 3. Valores médios de umidade da carcaça dos alevinos de lambari do rabo vermelho Astianax sp F.

Estas médias mostram a eficiência da defumação dos lambaris. Os valores de UM dos peixes defumados ficaram um pouco abaixo dos valores observados por Morais et al (1996) e Cardinal et al. (2001) que foi de 65\% para filés de truta e salmão, respectivamente, e Gonçalves e PrenticeHernandez (1998) que foi de 59,79\% para filés de anchova. Este último valor foi observado para a umidade dos peixes defumados entre os tempos de 90 e 180 minutos. É importante ressaltar que foram defumadas peixes inteiros eviscerados, com músculos relativamente finos.
De acordo com Schmidt (2004) há uma relação inversa entre os teores de umidade e lipídeos, que são influenciados pela época do ano, idade, sexo e estado nutricional dos peixes. De maneira geral a umidade da maioria dos pescados varia entre 60 a $85 \%$ do peso total dos peixes. Portanto, para evitar qualquer influência na análise foram utilizados peixes de mesma categoria de peso, e pescados no mesmo local. Segundo Souza et al. (2005) a gordura também pode influenciar as perdas durante o processo de defumação, pois peixes com mais gordura perdem menos água, e neste experimento o aumento nas 
perdas nos maiores períodos de defumação pode ser explicada pelos lambaris serem magros.

Para os demais variáveis analisadas $(\mathrm{PB}, \mathrm{LP}$ e $\mathrm{MM})$ não foram observadas significativas $(\mathrm{P}>0,05)$ dos diferentes tempos de exposição à defumação. O aumento no teor de MM de $10,83 \%$ para $13,53 \%$ que pode ser decorrente das desidratação, ação da fumaça e acúmulo de sal (cloreto de sódio) durante o processo de salga úmida e defumação (SOUZA et al., 2004).

As médias de PB foram semelhantes aos obtidas por Souza et al. (2005), que observaram 30,37, 29,32 e $29,52 \%$ de PB para o filé de tilápia defumado para os peixes que pesavam entre 500-600, 601-700 e 701-800g, respectivamente. Souza et al. (2004) observaram 19,20 e $25,27 \%$ de PB para a tilápia inteira in natura e defumada, respectivamente e 25,65 e $33,04 \%$ de PB para filé in natura e defumado. Gonçalves e Prentice-Hernandez (1998) observaram 16,80 e $22,30 \%$ de PB para filés in natura e defumados de anchova. Estas diferenças entre os defumados e in natura é explicada pela perda de umidade concentrando a proteína. Oliveira e Inhamuns (2005) encontraram teores de proteína de $20,35 \%$ para filé defumado e $21,32 \%$ para o músculo abdominal do pirarucu defumado.

Os teores de LP da matéria prima utilizada para a defumação determina a qualidade do produto, pois evita que o músculo se torne quebradiço. Os valores de LP observados neste experimento variaram de 2,53 a $3,84 \%$ para os tratamentos de 270 e 90 minutos, respectivamente. Os teores de gorduras podem influenciar nas perdas durante o processo de defumação, porque peixes commaior teor de gorduras perdem menos água no processamento (SOUZA et al., 2005). Mas neste experimento houve pequena perda com o aumento do período de defumação sem diferença significativa, isto é explicada pela baixo percentual de gordura destes peixes. Souza et al. (2005) relatam ter observado valores de 3,51, 3,69 e 3,49\% de LP para o filé de tilápia defumado de peixes entre 500-600, 601-700 e 701-800g e 3,49 e
$3,55 \%$ de LP para filés defumados com e sem pele, respectivamente. Souza et al. (2004) relatam que a tilápia inteira apresenta $8,06 \%$ de LP e a defumada $11,31 \%$ de LP, estes autores também observaram 2,55 e 4,47\% de LP para filé in natura e defumado, respectivamente. Gonçalves e Prentice-Hernandez (1998) observaram 12,43 e 15,31\% de LP para filés in natura e defumado de anchova. Estas diferenças entre as amostras in natura e defumado podem ser explicadas pela perda de umidade das amostras. Oliveira e Inhamuns (2005) observaram que o filé de pirarucu defumado apresenta $0,71 \%$ de LP e o músculo abdominal defumado $2,45 \%$ de LP.

A percentagem de $\mathrm{MM}(10,83$ a $13,53 \%)$ observada no atual experimento é considerada alto em relação a outros trabalhos, mas é importante ressaltar que os peixes foram utilizados inteiros com cabeça, pele, espinhas, coluna vertebral e nadadeiras aumentado os índices de matéria mineral. $\mathrm{O}$ aumento nos valores com a exposição à fumaça, é explicada pela perda de umidade e acumulo de cloreto de sódio. Souza et al. (2005) relatam que o teor de MM variou de 5,25, 5,31 e 5,30\% para os filés defumados dos animais entre 500-600, 601700 e 701-800g de peso e 5,42 e 5,09\% de MM para os filés defumados com e sem pele. Souza et al. (2004) defumando tilápias, relatam ter observado 3,41 e 7,30\% de MM para a tilápia inteira in natura e defumada, respectivamente, e 1,04 e $5,13 \%$ de MM para o filé in natura e defumada. Gonçalves e Prentice-Hernandez (1998) observaram 1,09 e $2,45 \%$ de MM para filés in natura e defumados de anchova, respectivamente. Os valores de matéria mineral do pirarucu, avaliado por Oliveira e Inhamuns (2005), foi de 3,54 e 3,50\% para o filé e o músculo abdominal defumado, respectivamente.

\section{Conclusão}

Conclui-se, que para a defumação de lambari do rabo vermelho Astyanax sp. F, os tempos de $225 \mathrm{~min} 7 \mathrm{seg}$ proporcionam o melhor rendimento e qualidade final do produto. 


\section{Referências}

BERAQUET, N. J.; MORI, E. E. M. Influência de diferentes métodos de defumação na aceitabilidade de cavalinha Scomber japonicus Houtt defumada. Coletânea do ITAL, Campinas, v. 14, n. 1, p. 1-25, 1984.

BOSCOLO,W. R.; FEIDEN, A.; ZORZO, A. L.; DEPARIS, A.; GROSSO, I. R. Características da carcaça do lambari (Astyanax altiparanae) capturados no Reservatório de Caxias, Rio Iguaçu, em diferentes classes de peso. In: CONGRESSO BRASILEIRO DE ENGENHARIA DE PESCA, 14., 2005, Fortaleza. Anais... Fortaleza: FAEP/BR, 2005. p. 1549-1550.

CARDINAL, M.; KNOCKAERT, C.; TORRISSEN, O.; SIGURGISLADOTTIR, S.; MORKORE, T.; THOMASSEN, M.; VALLET, J. L. Relation of smoking parameters to the yield, colour and sensory quality of smoked Atlantic salmon (Salmo salar). Food Research International, Oxford, v. 34, n. 6, p. 537-550, 2001.

CASSEMIRO, F. A. S.; HAHN, N. S.; FUGI, R. Avaliação da dieta de Astyanax altiparanae Garutti \& Britski, 2000 (Osteichthyes, Tetragonopterinae) antes e após a formação do reservatório de Salto Caxias, Estado do Paraná, Brasil. Acta Scientiarum, Maringá, v. 24, n. 2, p. 419-425, 2002.

FERREIRA, M. W.; SILVA, V. K.; BRESSAN, M. C.; FARIA, P. B.; VIEIRA, J. O.; ODA, S. H. I. Pescados processados: maior vida de prateleira e maior valor agregado. Lavras: UFLA, 2002. (Boletim Técnico - Série Extensão Rural).

GONÇALVES, A. A.; PRENTICE-HERNANDEZ, C. Defumação liquida de anchova (Pomatomus saltatrix): efeito do processamento nas propriedades químicas e microbiológicas. Ciência e Tecnologia de Alimentos, Campinas, v. 18, n. 4, p. 1-12, 1998.

HORWITZ, W. (Ed.) Oficial methods of analysis of association of official analytical chemists. 17.ed. Arlington: AOAC, 2000. v. 1-2.

MACEDO-VIEGAS, E. M.; SOUZA, M. L. R. Préprocessamento e conservação de pescado produzido em piscicultura. In: CYRINO, J. E. P.; URBINATTI, E. C.; FRACALOSSI, D. M.; CASTAGNOLLI, N. (Org.). Tópicos especiais em piscicultura de água doce. São Paulo: TecArt, 2004. v. 1, p. 405-480.

MORAIS, C.; MACHADO, T. M.; TAVARES, M.; TAKEMOTO, E.; YABIKU, H. Y.; MARTINS, M. S.
Defumação líquida da truta arco-íris (Oncorhyncus mykiss): Efeitos do processamento e da estocagem nas propriedades físicas, químicas e sensoriais. Revista do Instituto Adolfo Lutz, São Paulo, v. 56, n. 2, p. 43-48, 1996.

NUNES, M. L. Defumação. In: OGAWA, M.; MAIA, E. L. (Eds.) Manual de pesca: ciência e tecnologia do pescado. São Paulo: Varelap, 1999. v. 1, p. 300-306.

OLIVEIRA, M. J. M.; INHAMUNS, A. J. Defumação a quente de diferentes cortes do pirarucu (Arapaima gigas CUVIER, 1829). In: CONGRESSO BRASILEIRO DE ENGENHARIA DE PESCA, 14., 2005, Fortaleza. Anais... Fortaleza: FAEP/BR, 2005. p. 1553-1554.

REIDEL, A.; FEIDEN, A.; BOSCOLO, W. R.; COSTA, A. C.; GROSSO, I. R. Características corporais do lambari (Astyanax sp. f.) capturado no Reservatório de Caxias, Rio Iguaçu, em diferentes classes de peso. In: CONGRESSO BRASILEIRO DE ENGENHARIA DE PESCA, 14., 2005, Fortaleza. Anais... Fortaleza: FAEP/ BR, 2005. p. 911-912.

SANCHEZ, L. Pescado matéria prima e processamento. São Paulo: Fundação Cargill, 1989.

SCHMIDT, E. C. Avaliação de filés de tilápias com e sem off-flavor submetidos ao processo de defumação. 2004. Trabalho de Conclusão de Curso (Graduação em Engenharia de Pesca) - Universidade Estadual do Oeste do Paraná, Toledo.

SOUZA, M. L. R.; BACCARIN, A. E.; MACEDO VIEGAS, E. M.; KRONKA, S. N. Defumação da Tilápia do Nilo (Oreochromis niloticus) inteira, eviscerada e filé: aspectos referentes às características organolépticas, composição centesimal e perdas ocorridas no processamento. Revista Brasileira de Zootecnia, Viçosa, v. 33, n. 1, p. 27-36, 2004.

SOUZA, M. L. R.; MACEDO-VIEGAS, E.M.; SOBRAL, P. J. A.; KRONKA, S. N. Efeito do peso de tilápia do Nilo (Oreochromis niloticus) sobre o rendimento e a qualidade de seus filés defumados com e sem pele. Ciência e Tecnologia de Alimentos, Campinas, v. 25, n. 1, p. 51-59, 2005.

UNIVERSIDADE FEDERAL DE VIÇOSA - UFV. SAEG: Sistema para análises estatísticas e genéticas. Versão 7.1. Viçosa: Ed. da UFV, 1997. Manual do usuário. 